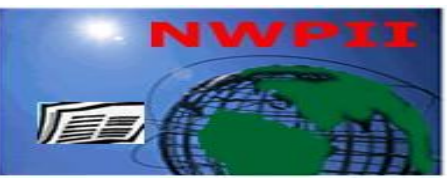

American Journal of Biomedical Sciences

ISSN: 1937-9080

nwpii.com/ajbms

\title{
In-utero Exposure to Maternal Diabetes Increase the Risk of Vascular Diseases in the F1 Offspring in Rats
}

\author{
Maher A Kamel", Shimaa A Mahmoud, Hanan Abo Elfetooh \\ Department of Biochemistry, Medical Research Institute, University of Alexandria, Egypt \\ Corresponding author: \\ Maher A Kamel \\ Assistant Professor of Biochemistry \\ Medical Research Institute, Alexandria University \\ 165- El Horreya Street \\ El Hadra, Alexandria \\ Egypt \\ Postal code: 21561 \\ Tel: +2-01227151191 \\ E-mail: maher.kamel@alexu.edu.eg \\ maherrashwan@hotmail.com
}

Received: 21 April 2014; | Revised:11 September 2014; | Accepted: 15 October 2014

\begin{abstract}
Background: Maternal diabetes is one of the fundamental intrauterine disturbances that have direct and long lasting consequences on the health of the offspring. The risk for an individual to develop various vascular diseases throughout life is hypothesized to be related to diabetic gestation.

Aim: The present study aimed to evaluate the postnatal levels of different independent risk factors for vascular diseases including homocysteine (Hcy), nitric oxide (NO), lipid profile, glucose homeostasis and insulin resistance in the rat offspring of diabetic mothers. The effect of postnatal feeding with high caloric diet (HCD) was also assessed.

Methods: Two groups of female Wistar rats were used (diabetic and control); diabetes was neonatally induced by STZ injection to 5-day old rats. Pregnancy was induced by mating control or diabetic females with normal healthy males overnight and the pregnancies were completed to term. After delivery the offspring were weaned to control diet (CD) or high-caloric diet (HCD) (Table 1) and followed up for 30 weeks. So the offspring groups were as following: F1 offspring of control mothers under control diet (CF1CD), F1 offspring of control mothers under HCD (CF1-HCD), F1 offspring of diabetic mothers under control diet (DF1-CD) and F1 offspring of diabetic mothers under HCD (DF1-HCD). Every 5 weeks $0.5 \mathrm{ml}$ blood samples were obtained from the 20 male and female rats for assessment of fasting blood glucose, insulin, triglycerides, cholesterol (total, HDL-C and LDL-C), homocysteine and nitric oxide end products (NOx).

Results: The results indicated that maternal diabetes caused an age-dependent alteration in glucose homeostasis and resulted in insulin resistance especially in male offspring. Also, lipid profile showed
\end{abstract}


elevation of triglycerides, cholesterol and LDL-C while HDL-C showed significant decline in the offspring of diabetic mothers. These disturbances in glucose and lipid metabolism were associated with elevated plasma level of Hcy from 25 week age and thereafter. Also, there was an elevation in the level of nitric oxide end products (NOx).

Conclusion: Maternal diabetes cause increased risk for vascular diseases in the offspring. The mechanisms of this predisposition involve disturbed lipid profile, insulin resistance, increased circulatory levels of Hcy (independent risk factor for vascular diseases) and nitric oxide end products. Male rat offspring appear to be more sensitive for the development of vascular diseases than female offspring and postnatal diet plays important role in this predisposition as the risk increases with high caloric diet.

Keywords: Fetal origin of disease, Diabetes, homocysteine, cardiovascular, Nitric oxide.

\section{Introduction}

The embryonic and fetal life represent the period of development where structural and functional features of an individual take place. Any alteration in the intrauterine environment at this critical stage of fetal development may have serious complications and life-long consequences $[1,2]$. Maternal diabetes is one of the paramount intrauterine disruptions that have damaging impact on the health of the offspring that can manifest directly and on the long term [3-6]. The risk for an individual to develop various vascular diseases throughout life is hypothesized to be related to diabetic gestation [6-8]. Also, many abnormal intrauterine conditions predispose the offspring to diabetes during later life and the same offspring were documented to develop vascular diseases which may suggest a causal relationship or a unifying mechanism of programming for the two conditions $[5,7,9,10]$.

Cardiovascular disease is the major cause of mortality and morbidity worldwide. It's well associated with various lifestyle habits like smoking and unhealthy diet as well as typical causes like male gender and older age. The classical risk factors for vascular diseases include insulin resistance, obesity, dyslipidemia and hypertension. These entire factors share a common crippling pathway for induction of atherosclerosis named "endothelial dysfunction" [11]. Nitric oxide is the main regulator of endothelial functions especially vasodilatation and also it has anti-inflammatory, anti-apoptotic, anti-thrombotic and anti-platelets aggregation effects. All of these play important role as a cardiovascular protective mechanism [12]. NO is synthesized by three isoforms nitric oxide synthases (NOS) enzymes; endothelial (eNOS), neuronal (nNOS) and inducible NOS (iNOS). The physiological constitutive production of NO involved in cardiovascular protection and homoeostasis is mediated by eNOS while excess NO production mediated by inducible isoform, iNOS has been suggested to mediate nitrative stress and cytotoxicity in a variety of pathological states $[12,13]$.

Insulin was documented to play a pivotal role in the regulation of NO synthesis in vasculature away from its metabolic effects through activation of protein kinase $B$ that directly activates vascular and myocardial eNOS leading to increased production of $\mathrm{NO}$ and cardiovascular protection [14]. So, the interruption of insulin signaling that associated with insulin resistance and type 2 diabetes may participate in the pathogenesis of cardiovascular complications.

The circulatory homocysteine (Hcy) is considered to be an inevitable risk factor and marker in assigning cardiovascular disease. As the link between high levels of circulatory homocysteine and cardiovascular disease remained mysterious for long time, an unlimited 
number of studies had a crystal clear purpose which was to provide more insights on the provident hypothesis that homocysteine is to be considered one of the crucial risk factors of cardiovascular disease $[15,16]$.

Prenatally at gestational day 15 , the embryos of maternal diabetes showed defective vasculogenesis and deranged production of angiogenic factors like vascular endothelial growth factor A (VEGFA), placental growth factor and prostaglandin $\mathrm{E}_{2}[17,18]$. The present study aimed to evaluate the postnatal levels of different independent risk factors for vascular diseases in the rat offspring of diabetic mothers.

\section{Animals and Method:}

\subsection{Chemicals}

Streptozotocin, was obtained from SigmaAldrich Chemie GmbH (Germany). DNase I, nuclease P1 and alkaline phosphatase were obtained from Bio-Basic (Canada).

\subsection{Animals}

The animal protocol was approved by the Institutional Animal Care and Use Committee at the Medical Research Institute- Alexandria University. Two groups of female Wistar rats were used (diabetic and control); Diabetes was induced in neonatal female rats by intraperitoneal injection of streptozotocin $(100 \mathrm{mg} / \mathrm{Kg})$ at postnatal day 5 (PND5) [19]. The chronic hyperglycemia was confirmed in those females after 12-14 weeks, as fasting blood glucose levels measured in tail vein blood by Glucometer (One Touch, Johnson and Johnson Co.) were more than $200 \mathrm{mg} / \mathrm{dl}$. Pregnancy was induced by mating control or diabetic females with normal healthy males overnight. Pregnancy was confirmed by the presence of vaginal mucus plug next morning. The pregnancies were completed to term. After delivery the offspring were weaned to control diet (CD) or high-caloric (HCD) diet (Table 1) and followed up for 30 weeks. So the offspring groups were as following: F1 offspring of control mothers under control diet (CF1-CD), F1 offspring of control mothers under HCD (CF1HCD), F1 offspring of diabetic mothers under control diet (DF1-CD) and F1 offspring of diabetic mothers under HCD (DF1-HCD).

Every 5 weeks $0.5 \mathrm{ml}$ blood samples were obtained from the 20 male and female rats for assessment of fasting blood glucose, insulin, triglycerides, cholesterol (total, HDL-C and LDL$\mathrm{C})$, homocysteine and nitric oxide end products (NOx).

\begin{tabular}{|c|c|c|}
\hline $\begin{array}{l}\text { Macronutrients } \\
\text { (g/kg diet) }\end{array}$ & $\begin{array}{l}\text { Control } \\
\text { diet } \\
\text { (CD) }\end{array}$ & $\begin{array}{c}\text { High- } \\
\text { caloric } \\
\text { diet } \\
\text { (HCD) }\end{array}$ \\
\hline Protein & 220 & 244 \\
\hline Carbohydrates & 631 & 593 \\
\hline $\begin{array}{l}\text { - Lard } \\
\text { - corn oil }\end{array}$ & $\begin{array}{l}- \\
43\end{array}$ & $\begin{array}{l}48 \\
20\end{array}$ \\
\hline Cellulose & 54 & 50 \\
\hline Vitamin mix & 10 & 10 \\
\hline Mineral mix & 40 & 35 \\
\hline $\begin{array}{l}\text { Total energy } \\
\text { (kcal/g diet) }\end{array}$ & 3.8 & 4.7 \\
\hline
\end{tabular}

\subsection{Methods}

\subsubsection{Routine measurements}

Blood glucose level, triglycerides, cholesterol, low density lipoprotein-cholesterol (LDL-C) and high density lipoprotein-cholesterol (HDL-C) levels were assayed using commercial available kits (Randox, UK). Insulin level was determined using EIA kit (Mercodia Sweden). The insulin resistance index (IRI) was derived using the homeostasis model assessment (HOMA) as follows: IRI $=$ fasting insulin $(\mu \mathrm{U} / \mathrm{ml}) \times$ fasting glucose $(\mathrm{mmol} / \mathrm{l}) / 22.5$ HOMA has been validated as useful method of assessing insulin resistance [20].

\subsubsection{Assay of homocysteine}

C 2014 by NWPII. All rights reserved 
Total homocysteine level was determined using Axis Homocysteine EIA assay (Germany). Protein bound homocysteine is reduced to free homocysteine and enzymatically converted to Sadenosyl-L-homocysteine ( $\mathrm{SAH}$ ) in a separate procedure prior to the immunoassay. The assay is based on competition between SAH in the sample and immobilised SAH bound to the walls of the microtitre plate for binding sites on a monoclonal anti-SAH antibody. After removal of unbound anti-SAH antibody, a secondary rabbit antimouse antibody labelled with the enzyme horse radish peroxidase (HRP) is added. The peroxidase activity is measured spectrophotometrically after addition of substrate, and the absorbance is inversely related to the concentration of total homocysteine in the sample.

\subsubsection{Assay of nitric oxide end products (nitrite and nitrate; NOx)}

The nitrite and nitrate (NOx) concentration was determined by simple Griess reaction [21]. Because the nitric oxide (NO) has a short half life $(2-30 \mathrm{sec})$, it is preferable to determine nitrite, the stable product of $\mathrm{NO}$ which may be further oxidized to nitrate. So, the Griess reaction was supplemented with the reduction of nitrate to nitrite by NADPH-dependent nitrate reductase. The assay consists of two steps: diazotization of sulphanilic acid with nitrite ion and coupling of this product with diamine which results in a measurable pink metabolite that measured at 540 $\mathrm{nm}$.

\subsubsection{Statistical analysis}

All data are presented as mean \pm SEM. A oneway analysis of variance (ANOVA) was performed on each variable and the Bonferroni statistics employed to compare the mean values from the offspring of diabetic mothers and the offspring of control mothers (under control diet and HCD). $t$-test was used to compare the mean values of females and those of males of the same group at the same age. The Kolmogorov-Smirnov test was used to study the normal distribution of the studied parameters. Differences were considered significant at $P<0.05$. All statistical analyses were performed using SPSS statistical software version 18 (SPSS, Chicago,IL).

\section{Results}

\subsection{Pregnancy outcome}

The results indicated that at term, diabetic pregnancies had significantly lower number of pups per litter. The birth weight of pups showed no significant change from control pups (Figure $1)$.

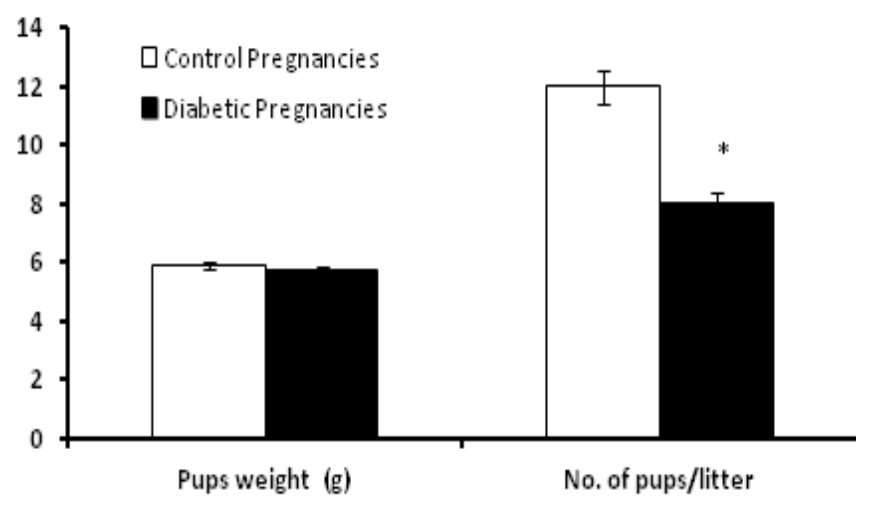

Fig (1): Number of pups per litter and pups weight of control and diabetic gestation. * ${ }^{*}$ Significant different compared to control group by $t$-test $(p<0.05)$

As the offspring rats grew older, the offspring of diabetic mothers showed higher weight than offspring of control mothers. The increase of body weight became significant on the offspring of diabetic mothers maintained under HCD at $20^{\text {th }}$ week age while the offspring maintained under $\mathrm{CD}$ became significantly heavier than control offspring at $30^{\text {th }}$ week old (Figure 2).

\subsection{Glucose homeostasis}

During the follow up period there was an age-dependent increase in the fasting blood glucose, insulin and HOMA-IR in all offspring. The offspring of diabetic mothers showed significantly higher levels of fasting glucose and insulin and showed more insulin resistance as indicated by higher HOMA-IR. The offspring under HCD showed the elevation earlier than those under $\mathrm{CD}$, especially male offspring (Table 2 ). At age 30 weeks most of the male offspring of 
maternal diabetes developed insulin resistance and significant elevation of fasting blood glucose level compared to control offspring under $\mathrm{CD}$ or HCD. The female offspring showed similar pattern of change but the elevation of HOMAIR and blood glucose were milder than that observed in males (Table 2).

Table (2): Glucose homoeostasis parameters in the different rat offspring of control and diabetic mothers at different ages

\begin{tabular}{|c|c|c|c|c|c|c|}
\hline & & & CF1-CD & CF1-HCD & DF1-CD & DF1-HCD \\
\hline \multirow{6}{*}{$\begin{array}{l}\text { Fasting blood } \\
\text { glucose (mg/dl) }\end{array}$} & \multirow[t]{2}{*}{$10^{\text {th }}$ week } & Male & $78 \pm 4.0$ & $74 \pm 4.5$ & $84 \pm 3.4$ & $97 \pm 3.5^{*}$ \\
\hline & & Female & $86 \pm 3.3$ & $84 \pm 3.1$ & $85 \pm 2.5$ & $88 \pm 3.0$ \\
\hline & \multirow[t]{2}{*}{$20^{\text {th }}$ week } & Male & $83 \pm 2.6$ & $85 \pm 3.2$ & $90 \pm 2.5$ & $102 \pm 3.1^{*}$ \\
\hline & & Female & $89 \pm 3.1$ & $94 \pm 3.4$ & $92 \pm 4.2$ & $96 \pm 3.5$ \\
\hline & \multirow[t]{2}{*}{$30^{\text {th }}$ week } & Male & $91 \pm 3.4$ & $94 \pm 3.1$ & $100 \pm 4.4$ & $128 \pm 4.2^{*}$ \\
\hline & & Female & $93 \pm 3.3$ & $96 \pm 2.3$ & $97 \pm 3.4$ & $115 \pm 3.6^{*, \neq}$ \\
\hline \multirow{6}{*}{$\begin{array}{l}\text { Insulin } \\
(\mu I U / m l)\end{array}$} & \multirow[t]{2}{*}{$10^{\text {th }}$ week } & Male & $6.0 \pm 0.12$ & $6.0 \pm 0.11$ & $6.5 \pm 0.15^{*}$ & $7.2 \pm 0.21^{*}$ \\
\hline & & Female & $6.5 \pm 0.11^{\neq}$ & $6.5 \pm 0.18^{\neq}$ & $6.7 \pm 0.15$ & $7.2 \pm 0.18^{*}$ \\
\hline & \multirow[t]{2}{*}{$20^{\text {th }}$ week } & Male & $7.4 \pm 0.13$ & $7.7 \pm 0.14$ & $8.2 \pm 0.17^{*}$ & $8.9 \pm 0.15^{*}$ \\
\hline & & Female & $7.9 \pm 0.14^{\neq}$ & $8.4 \pm 0.17^{*, \neq}$ & $8.4 \pm 0.16^{*}$ & $8.6 \pm 0.13^{*}$ \\
\hline & \multirow[t]{2}{*}{$30^{\text {th }}$ week } & Male & $7.9 \pm 0.18$ & $8.3 \pm 0.16$ & $10.1 \pm 0.15^{*}$ & $10.79 \pm 0.18^{*}$ \\
\hline & & Female & $7.7 \pm 16$ & $8.6 \pm 0.12^{*}$ & $8.64 \pm 0.18^{*}$ & $9.11 \pm 0.16^{*}$ \\
\hline \multirow[t]{6}{*}{ HOMA-IR } & \multirow[t]{2}{*}{$10^{\text {th }}$ week } & Male & $1.2 \pm 0.04$ & $1.2 \pm 0.03$ & $1.3 \pm 0.04$ & $1.7 \pm 0.04^{*}$ \\
\hline & & Female & $1.4 \pm 0.05^{\neq}$ & $1.3 \pm 0.04$ & $1.4 \pm 0.05$ & $1.6 \pm 0.03^{*}$ \\
\hline & \multirow[t]{2}{*}{$20^{\text {th }}$ week } & Male & $1.5 \pm 0.03$ & $1.6 \pm 0.04$ & $1.8 \pm 0.04^{*}$ & $2.2 \pm 0.04^{*}$ \\
\hline & & Female & $1.7 \pm 0.04^{\neq}$ & $1.9 \pm 0.05^{*, \neq}$ & $1.9 \pm 0.04^{*}$ & $2.0 \pm 0.04^{*}, \neq$ \\
\hline & \multirow[t]{2}{*}{$30^{\text {th }}$ week } & Male & $1.8 \pm 0.05$ & $1.9 \pm 0.04$ & $2.5 \pm 0.04^{*}$ & $3.4 \pm 0.05^{*}$ \\
\hline & & Female & $1.8 \pm 0.05$ & $2.0 \pm 0.04$ & $2.1 \pm 0.03^{*}$, & $2.6 \pm 0.03^{*, \neq}$ \\
\hline
\end{tabular}

Data presented as Mean \pm SEM.

* Significantly different compared to control group using ANOVA $(\mathrm{p}<0.05)$

* Significant difference of females compared to males of the same group at the same age by $t$-test $(\mathrm{p}<0.05)$

\subsection{Lipid profile}

The results of lipid parameters were presented in figures 3-6. All parameters showed disturbances from early life in the offspring of maternal diabetes especially males under HCD. Male offspring showed a significantly higher levels of cholesterol, triglycerides and LDL-C and lower level of HDL-C than control values from the $5^{\text {th }}$ week of age and with ageing the extension of these changes were exaggerated (Fig 3A-6A). The female offspring showed similar but milder pattern of changes as males and the significant changes observed mainly in the offspring under HCD. Also, feeding HCD to control offspring resulted in increased level of triglycerides at $25^{\text {th }}$ week of age irrespective of sex (Fig 3). 


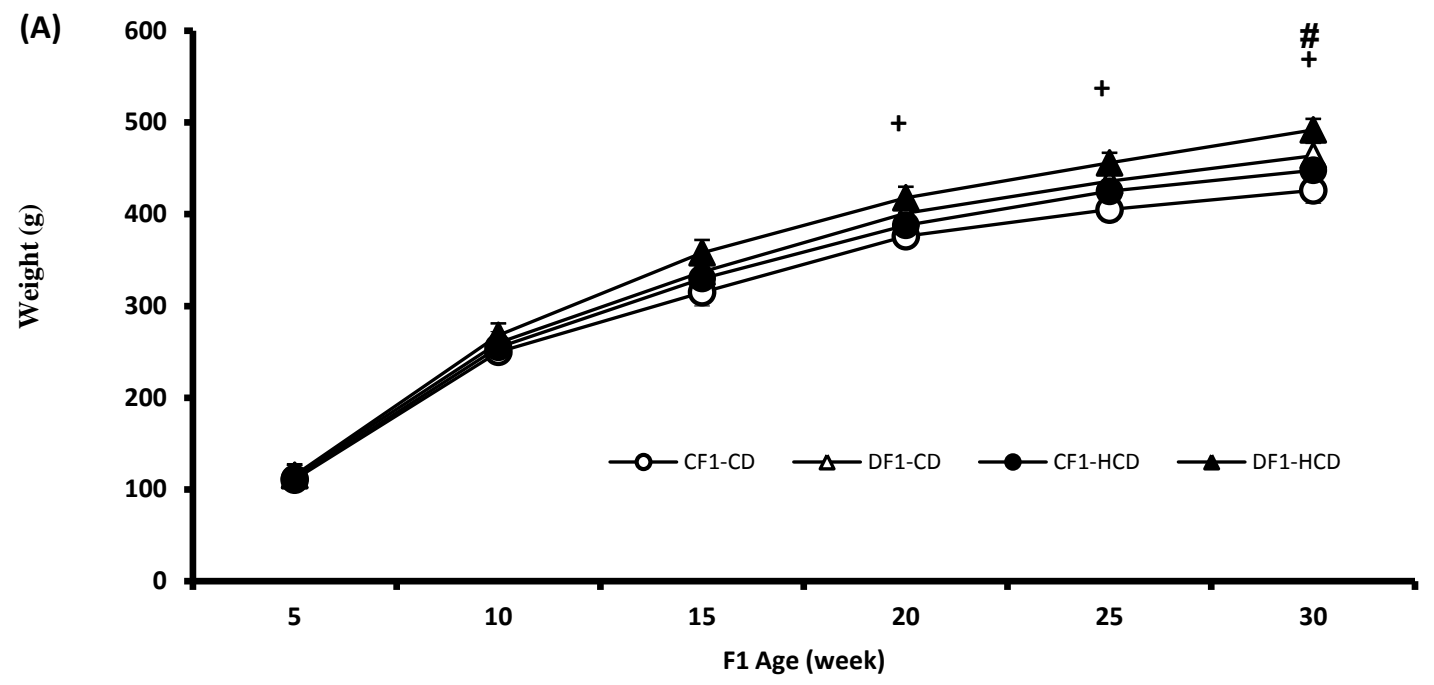

(B)

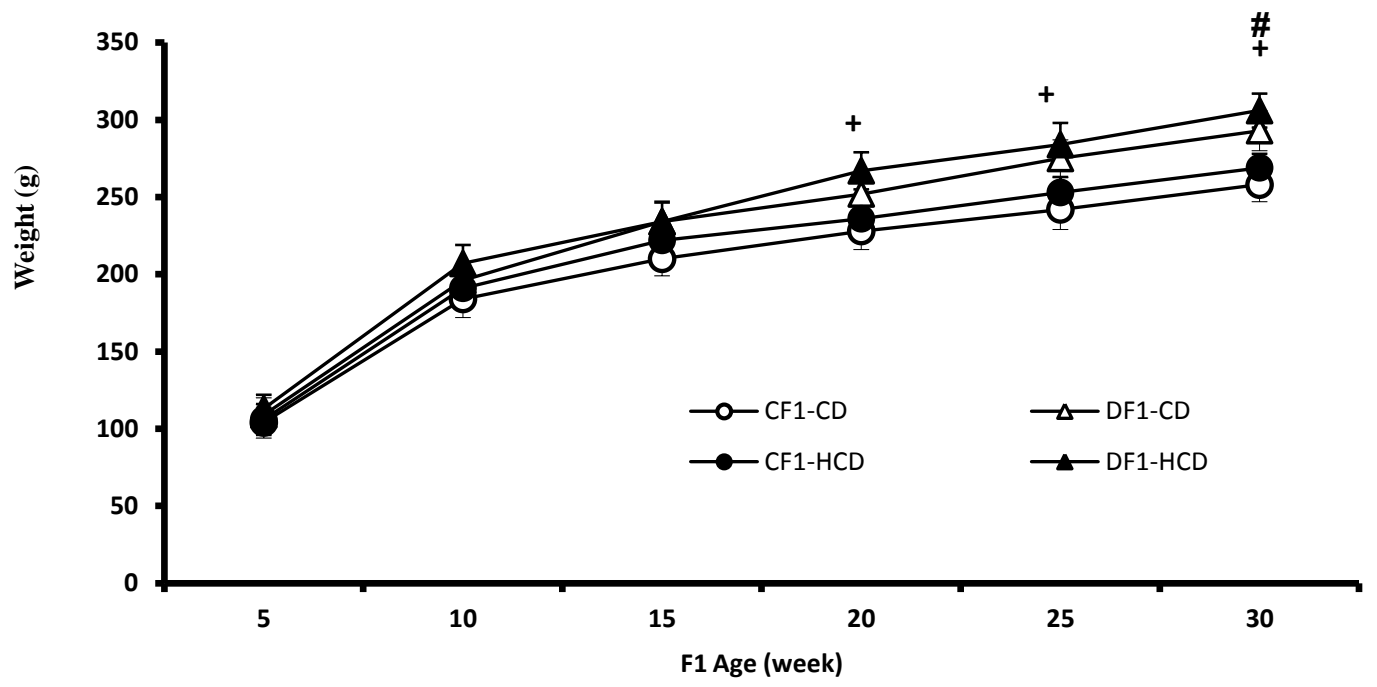

Figure (2): Age dependent change in weight in male (A) and female (B) F1 offspring under control and HCDdiet. Each point represent mean of 100 measurements (\# and + represent a significant difference between DF1-CD and DF1-HCD rats compared to CF1-CD rats respectively, Using ANOVA p<05)

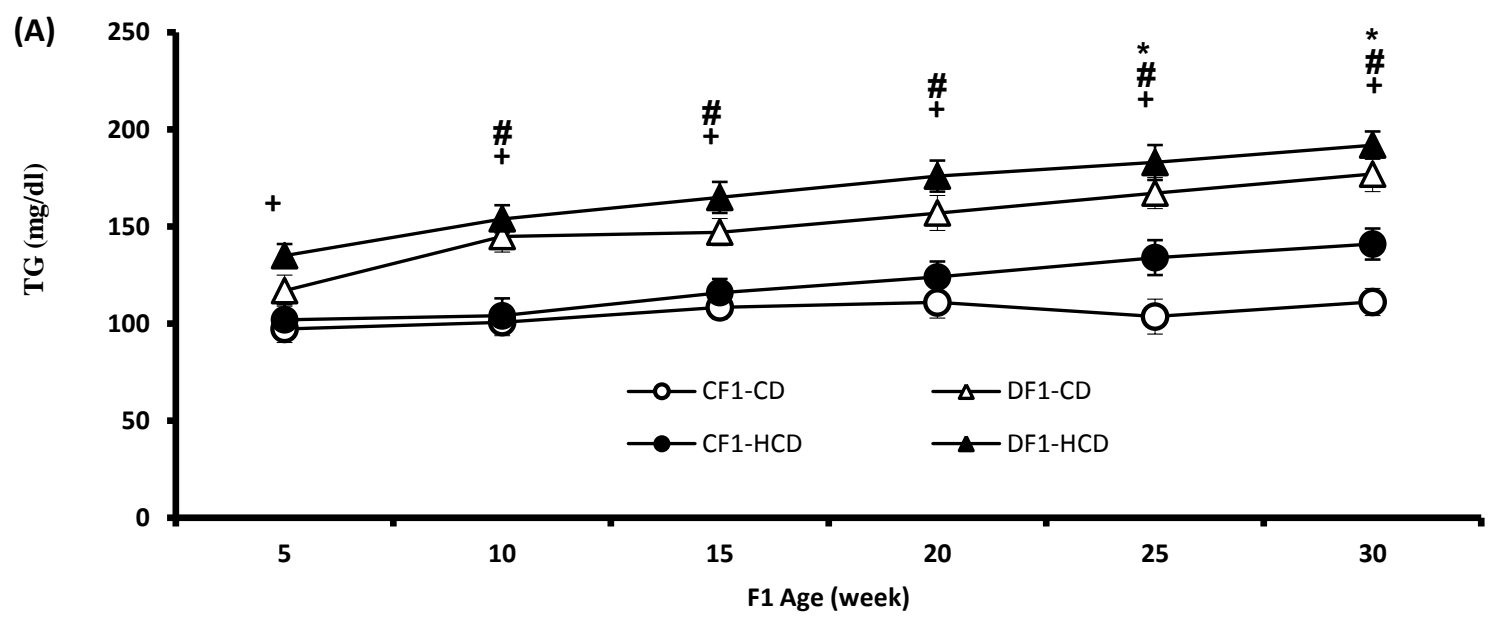




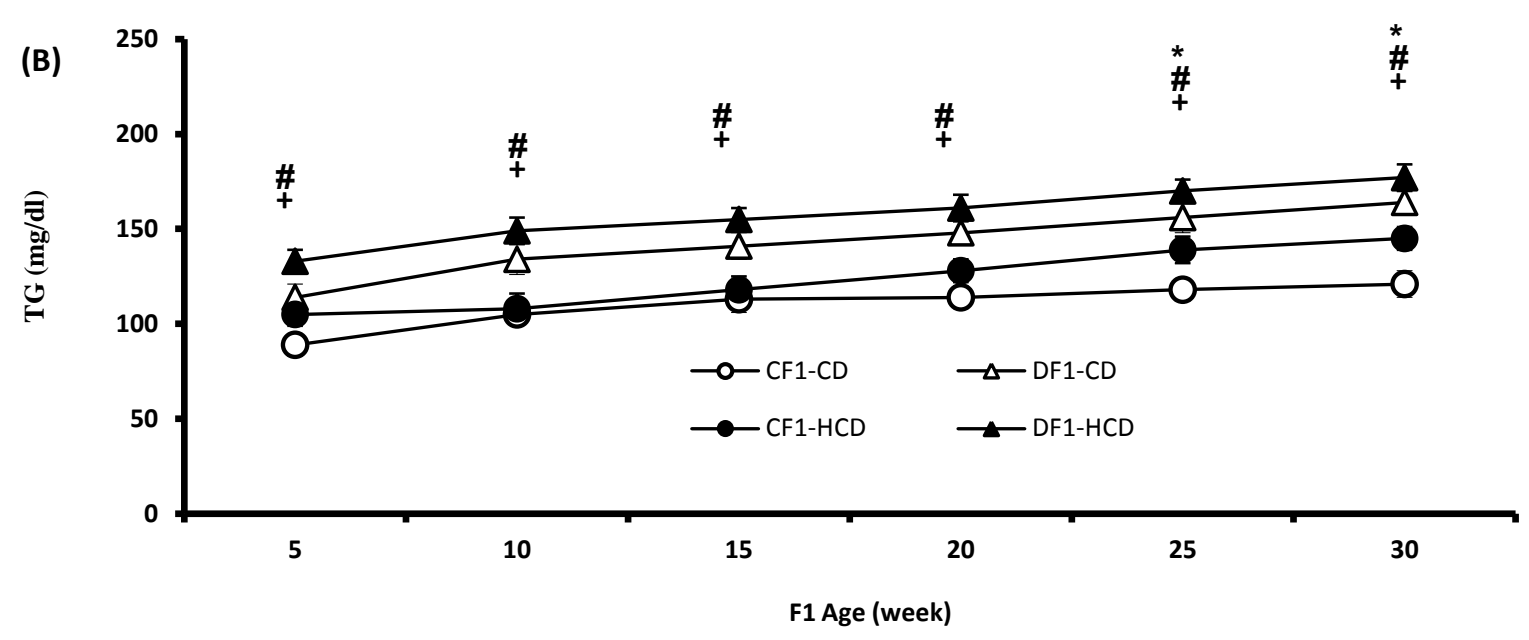

Figure (3): Age dependent change in triglycerides levels in male (A) and female (B) F1 offspring under control and HCD-diet. Each point represent mean of 20 measurements (*, \# and + represent a significant difference betweenCF1-HCD, DF1-CD and DF1-HCD rats compared to CF1-CD rats respectively, Using ANOVA p<05)
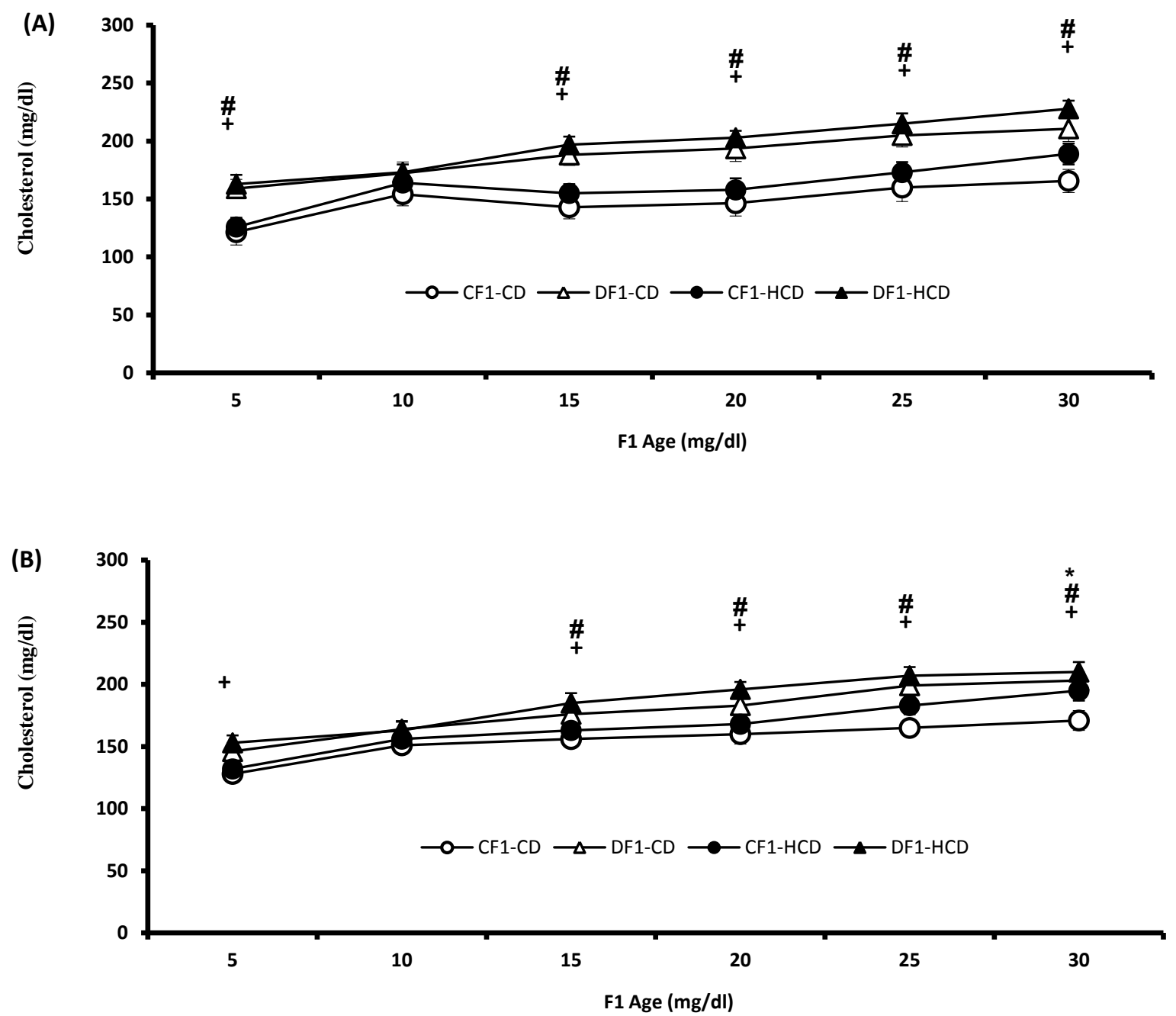

Figure (4): Age dependent change in cholesterol levels in male (A) and female (B) F1 offspring under control and HCD-diet. Each point represent mean of 20 measurements $\left(^{*}\right.$, \# and + represent a significant difference between CF1-HCD, DF1-CD and DF1-HCD rats compared to CF1-CD rats respectively, Using ANOVA p<05) 

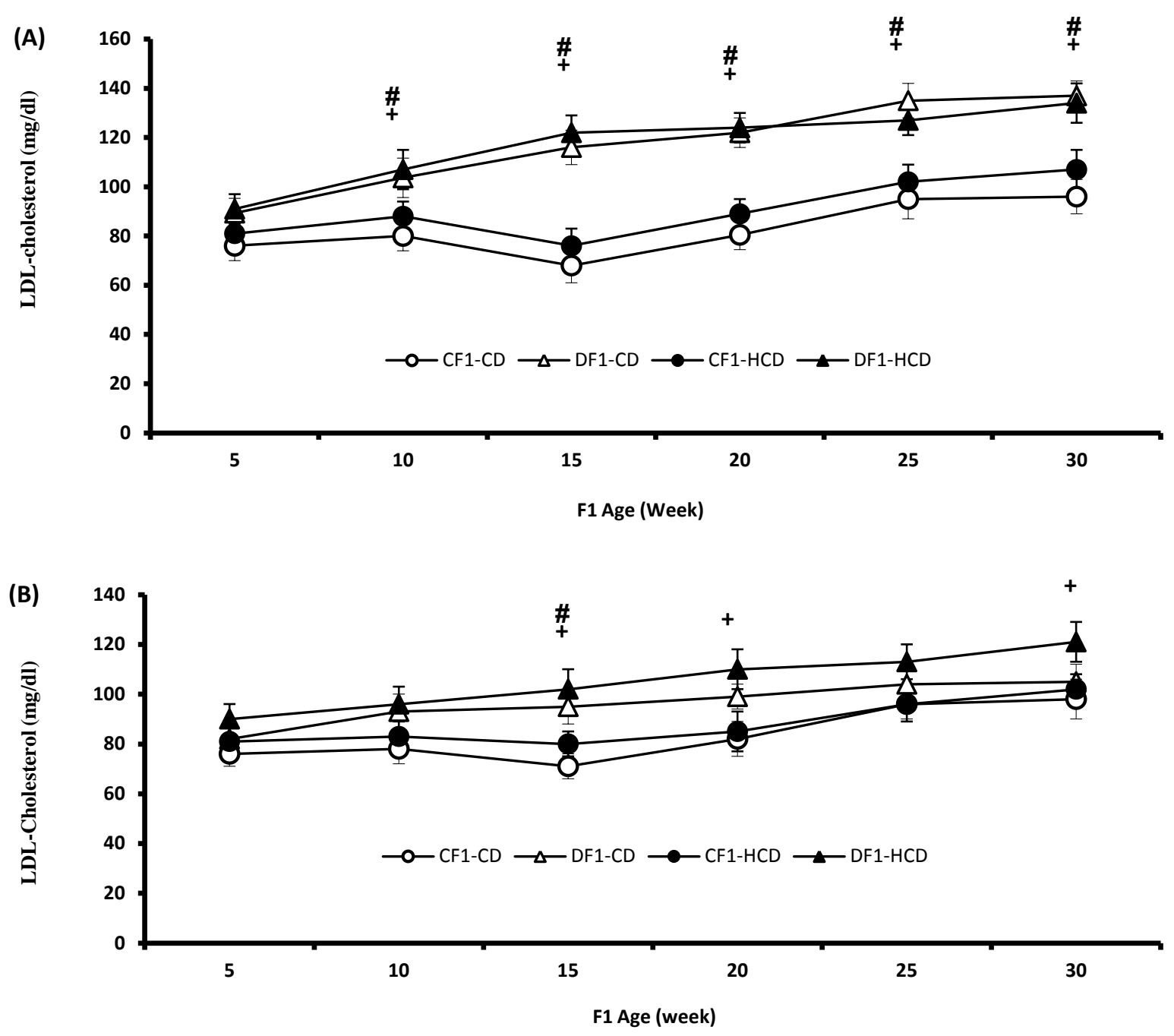

Figure (5): Age dependent change in LDL-cholesterol levels in male (A) and female (B) F1 offspring under control and HCD-diet. Each point represent mean of 20 measurements (\# and + represent a significant difference between DF1-CD and DF1-HCD rats compared to CF1-CD rats respectively, Using ANOVA p<05)

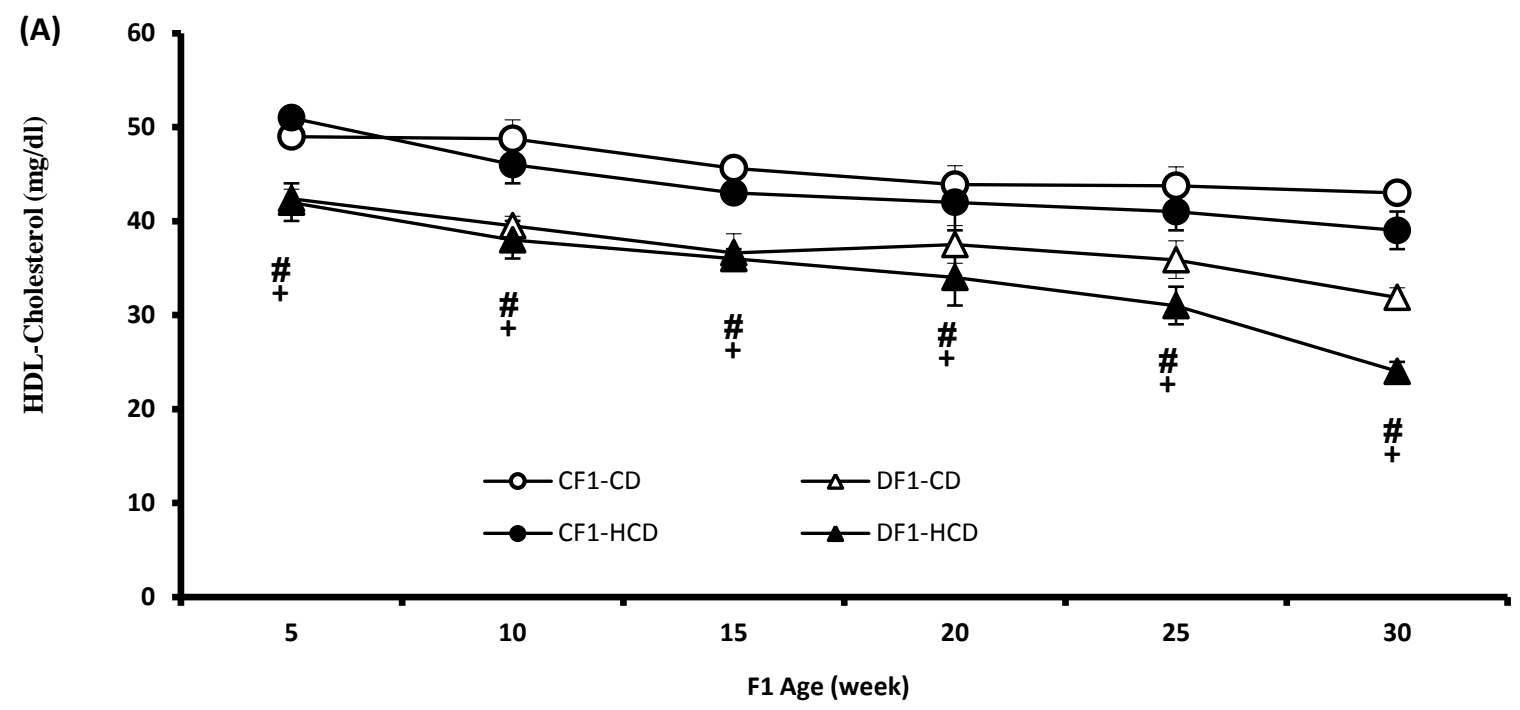




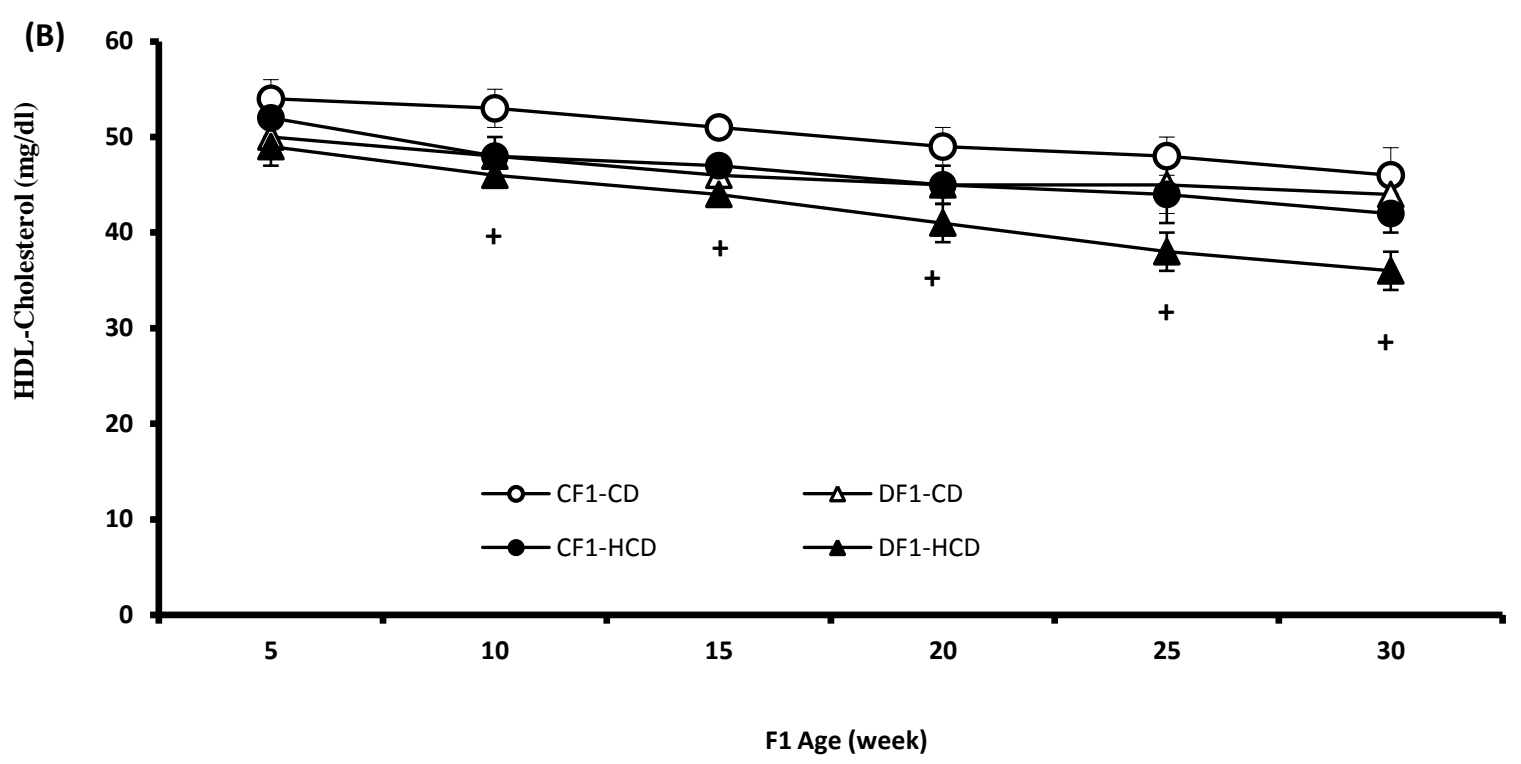

Figure (6): Age dependent change in HDL-cholesterol levels in male (A) and female (B) F1 offspring under control and HCD-diet. Each point represent mean of 20 measurements (\# and + represent a significant difference between DF1-CD and DF1-HCD rats compared to CF1-CD rats respectively, Using ANOVA p<05)
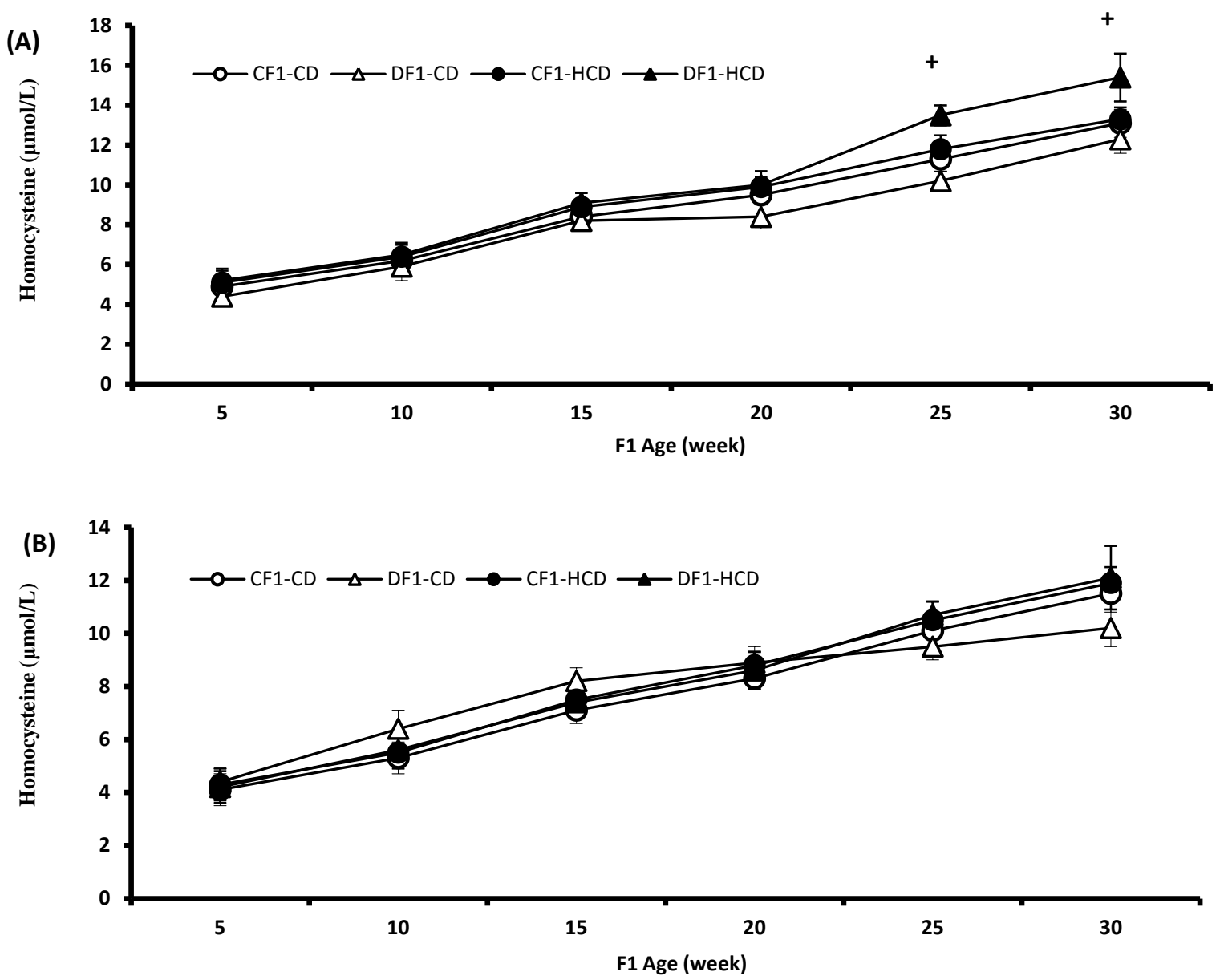

Figure (7): Age dependent change in homocysteine levels in male (A) and female (B) F1 offspring under control and HCD-diet. Each point represent mean of 20 measurements (+ represents a significant difference between DF1$\mathrm{HCD}$ rats compared to CF1-CD rats Using ANOVA p <05) 


\subsection{Homocysteine level}

Figure 7 summarizes the results of plasma homocysteine level. All offspring showed agedependent increase of the homocysteine level. The male offspring of diabetic mothers under HCD showed significantly higher level from $25^{\text {th }}$ week of age and thereafter while those males under $\mathrm{CD}$ showed no significant changes compared to control offspring (Fig 7A). Also, female offspring of diabetic mothers even under HCD showed no changes compared to control (Fig 7B).

\subsection{Nitric oxide products (NOx)}

The level of nitric oxide products showed an age-dependent increase in all offspring (Fig 8). During early life no significant changes were detected between the offspring of diabetic and control mothers. At $25^{\text {th }}$ week age the male offspring of diabetic mothers showed a significant elevation in NOx compared to control males irrespective of the type of diet (Fig 8A). Female offspring showed this elevation at later age $\left(30^{\text {th }}\right.$ wee $)($ Fig $8 \mathrm{~B})$

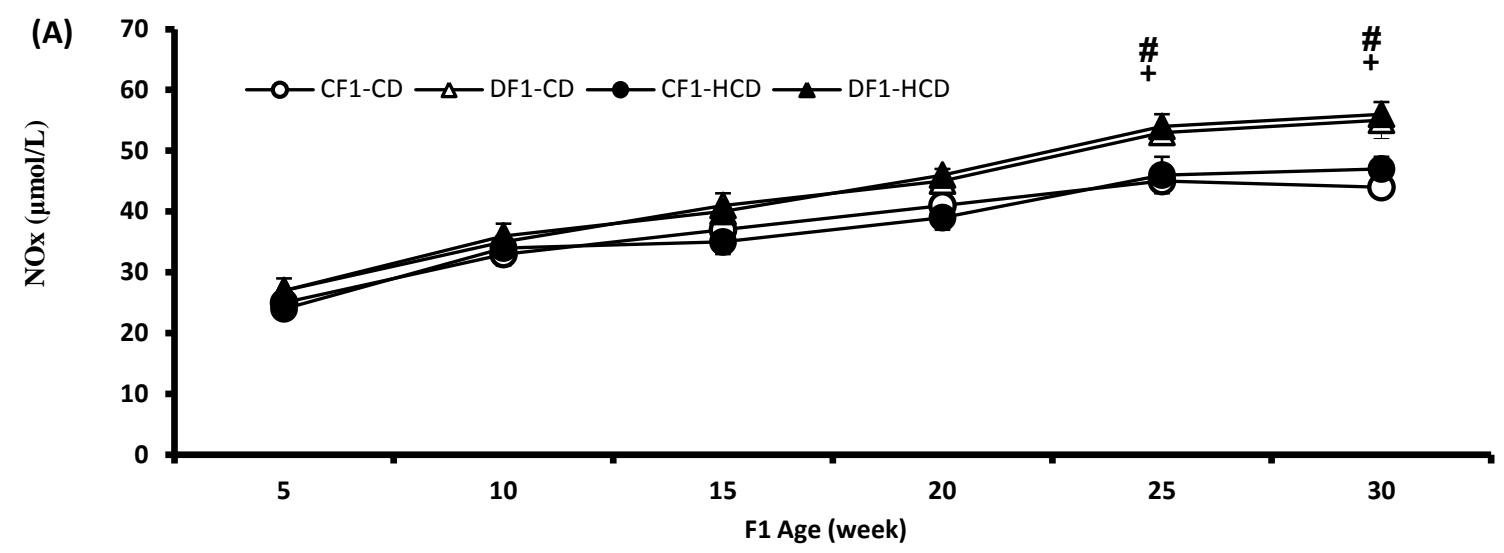

(B)

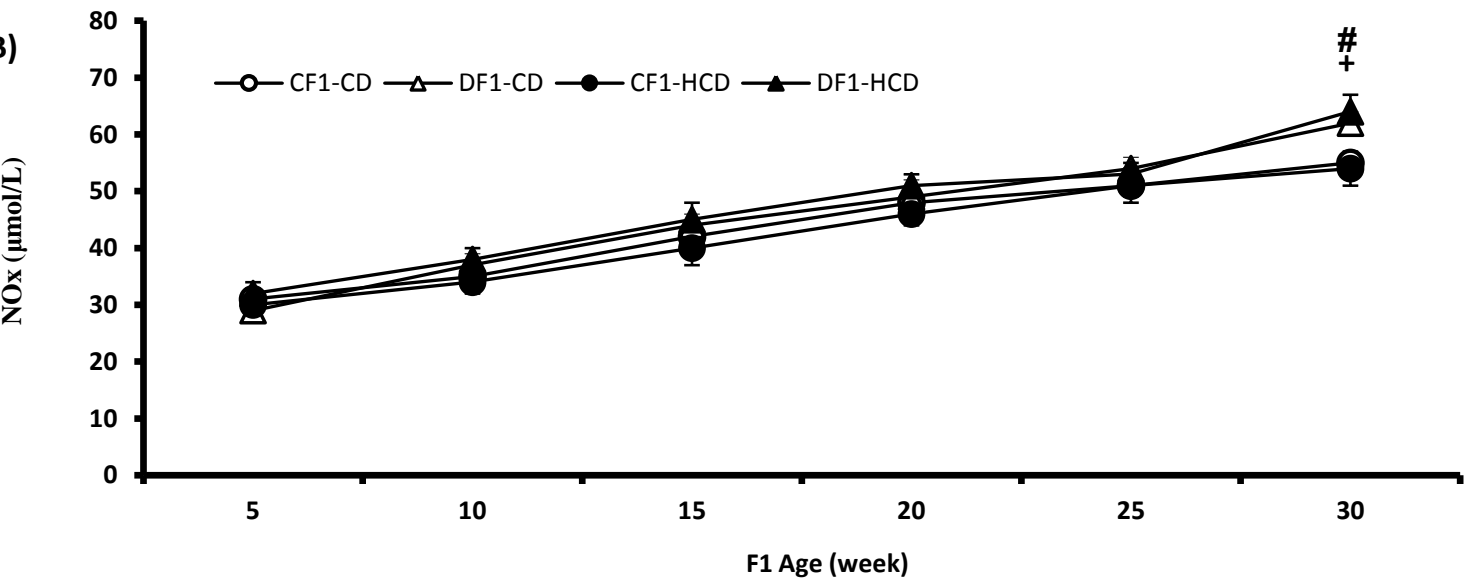

Figure (8): Age dependent change in NOx levels in male (A) and female (B) F1 offspring under control and HCD-diet. Each point represent mean of 20 measurements (\# and + represent a significant difference between DF1$\mathrm{CD}$ and DF1-HCD rats compared to CF1-CD rats respectively, Using ANOVA p <05)

\section{Discussion}

Maternal diabetes is a recognized medical problem for both of the mother and her offspring. The objective of this study was to determine the effect of maternal diabetes on the offspring's tendency to develop lifelong vascular diseases. As mentioned previously, the intrauterine environment shapes and programs the health of an individual throughout life. These long-term effects are cited as the Developmental Origins of Health and Disease (DOHaD) concept $[1,8,22]$. 
However, in this study the rat pups of diabetic mothers showed non-significant lower birth weight compared to control pups, many previous studies $[17,18,23]$ documented a prenatal intrauterine growth retardation in the rat fetuses of diabetic mothers which had to be compensated by a fast catch-up growth (CUG) which is defined as an accelerated rate of infant growth during the postnatal period [24]. Numerous studies have illustrated a concrete link between the catch-up growth in infancy and the development of coronary disease in adulthood and this link lead to the necessity to restrict the postnatal catch-up growth in order to prevent or even reasonably decrease cardiovascular risk factors by the adherence to low-fat diet [25-27]. In line with the results of the present study concerning postnatal weight, Singhal et al demonstrated that the rapid postnatal weight gain and the administration of high caloric nutrients are associated with cardiovascular risk factors as developing insulin resistance in adulthood [28]. That clarifies the reason why the animals on high caloric diet gained more weight rapidly rather than the ones under controlled diet and that had a preeminent effect on developing higher risk factors of cardiovascular disease. The postnatal weight gain is considered as a radical cause of developing insulin resistance in early childhood that persists to adulthood causing various metabolic disorders and mainly a major risk factor for cardiovascular diseases [29].

The sex and postnatal diet appear to affect the susceptibility of the offspring for vascular diseases. The male offspring under high-caloric diet (HCD) are more risky for the development of vascular diseases. A backing up evidence that male offspring of diabetic mothers are more vulnerable toward developing cardiovascular disease is that male offspring showed more significant higher levels of cholesterol and triglycerides and disruption in LDL-C and HDL$\mathrm{C}$ values which all are considered to be vital parameters associated with risk for cardiovascular disease [30,31]. Meanwhile female offspring only showed mild change in the stated parameters compared with the change in male ones.

These variations in lipid profile are the logic consequences of the development of insulin resistance in the offspring. Changes in glucose homeostasis and insulin resistance were observed in the offspring particularly the ones on high caloric diet. Insulin is evidently the dynamic regulator of glucose, lipid and protein metabolism. It suppresses hepatic glucose and triglycerides production and inhibits adipose tissue lipolysis and the release of fatty acid into the blood [32]. Insulin plays a potent role in hepatic lipoprotein regulation including triglyceride secretion and blood lipid clearance [33]. So insulin resistance is a non negotiable causative of numerous metabolic disruptions.

Apart from its metabolic roles, insulin plays important protective effect on cardiovascular system through regulation of $\mathrm{NO}$ production through AKT/PKB-eNOS signaling pathway [14]. NO plays a pivotal role as a second messenger for insulin mediated survival effect in the cardiovascular system [34]. The impairment of insulin signaling in the vascular system due to insulin resistance may participate in the development of endothelial dysfunction the leading cause of cardiovascular diseases.

Insulin was reported to increase NO production in vasculature through phosphorylation of eNOS and inhibit the production of superoxide anion $\left(\mathrm{O}_{2}\right)^{)^{-}}$production by NADPH oxidase that prevent the formation of peroxynitrite radical $\left(\mathrm{ONOO}^{-}\right)$from $\mathrm{NO}$ and $\left(\mathrm{O}_{2}\right)^{--}$[35]. Also, insulin inhibits iNOS expression and protect vascular system from excess NO production and nitrative stress [14]. The endothelial dysfunction could be due to decreased eNOS expression and activity, however it is well documented that the risk factors of cardiovascular diseases are associated with increased expression of eNOS [36,37]. The results of the present study indicated increased level of $\mathrm{NO}$ end products (NOx) in the offspring of diabetic mothers from the $25^{\text {th }}$ week of age in males and $30^{\text {th }}$ week of age in females. There are different approaches that could explain the enhanced level of NOx associated with increased other risk factors of vascular diseases; dyslipidemia and insulin resistance. Previously we reported an age dependent exaggeration of ROS production and oxidative stress in the offspring of diabetic mothers [38] this oxidative state may be the cause 
of the induction effect of hydrogen peroxide on the expression of eNOS at transcriptional and post-transcriptional level generating high level of NOx [39]. The resulting NO from highly expressed eNOS is degraded by reaction with $\left(\mathrm{O}_{2}\right)^{-}$to form peroxynitrite; a potent oxidizing agent that oxidize tetrahydrobiopterin $\left(\mathrm{BH}_{4}\right)$; a critical cofactor for NO synthesis by NOS. In the absence of $\mathrm{BH}_{4}$ the NOS produce $\left(\mathrm{O}_{2}\right)^{--}$instead of $\mathrm{NO}$ in a process referred as NOS uncoupling [40]. All of these reduce the bio-availability of $\mathrm{NO}$ and resulting in endothelial dysfunction.

Second explanation of enhanced NOx production; related to insulin resistance that was detected in those offspring of diabetic mothers at $20^{\text {th }}$ week of age which preceded the increase in the NOx level. The insulin resistance resulted in impaired insulin signaling in the vasculature which may break the inhibitory action of insulin on the expression of iNOS. Also, insulin resistance state is accompanied by mild chronic inflammation that favors induction of iNOS which produces large amount of $\mathrm{NO}$ and may cause nitrative stress. Therefore, the blunted insulin signaling together with reduced bioavailability of NO may predispose vasculature for endothelial dysfunction which may further impair insulin effect due to compromised delivery of glucose and insulin to the tissues [14].

Likewise, only male offspring of diabetic mothers under high caloric diet showed a remarkable gradual elevation in the homocysteine (Hcy) levels in plasma from $25^{\text {th }}$ week of age while females showed no significant change. Hcy is an intermediate sulfur-containing amino acid formed by demethylation of the essential amino acid methionine during its conversion to cysteine. Numerous studies have fairly demonstrated that elevated homocysteine concentrations in plasma are associated with a heightened risk of cardiovascular disease. Accumulating body of evidences prove the inevitable correlation between homocysteine levels in plasma and the risk for cardiovascular disease [15,16,41].

Guilland et al stated the consideration of Hcy as an independent risk factor for cardiovascular disease and also strongly suggested that Diabetes and disruptions in glucose homeostasis may be associated with moderately elevated homocysteine concentrations [42]. Also, it was proposed that abnormal Hcy level is linked to abnormal lipid metabolism and derangement in lipid concentrations in blood. As the levels of blood cholesterol, triglycerides, LDL and HDL were noted to markedly change in correspondence with alteration in homocysteine levels [43]. Derangements in the insulin level and glucose homoeostasis appear to be involved in the abnormal level of Hcy observed in the present study. Meigs et al illustrated hyperhomocysteinemia is associated with high levels of insulin accompanying to insulin resistance [44]. Other studies detected the similar pattern just to add more clear evidence that there is a decisive consistency between Hcy high levels and high concentrations of FBS and insulin manifested in insulin resistance condition [45].

Homocysteine levels have been clearly linked to lifestyle and nutritional habits. Though Homocysteine is not obtained from diet [46], Willette et al projected a reasonably enlightening theory that calorie restriction with adequate nutrition is positively effective in keeping Hcy levels within normal range and protects against cardiovascular disease [47]. Hcy levels are commonly higher in men rather than women [48].

High levels of Hcy are documented to have detrimental effects on endothelial dysfunction $[15,16,49]$. Hcy is characterized by its prooxidative properties that may induce oxidative stress which resulted in degradation of NO. Although Hcy was documented to impair endothelial NO production [50], many other studies demonstrate the mechanism of endothelial dysfunction induced by homocysteine involves its role in promoting nitric oxide levels [51,52].

From the results of the present study we concluded that maternal diabetes cause increased risk for vascular diseases in the offspring. The mechanisms of this predisposition involve disturbed lipid profile, insulin resistance, increased circulatory levels of Hcy (independent risk factor for vascular diseases) and nitric oxide end products. Male rat offspring appear to be more sensitive to the development of vascular diseases than female offspring and postnatal diet plays important role in this predisposition as the risk increases with high caloric diet. 


\section{Acknowledgements}

This study is a part of project entitled "IntraUterine programming of adult diabetes: an experimental study" supported by STDF (Science and Technology Development Fund)-Egypt.

\section{References}

1. Lebenthal E., Bier D.M. Novel concepts in the developmental origins of adult health and disease. The Journal of Nutrition, 2007;137(4):1073-1075.

2. Barnes S., Ozanne S. Pathways linking the early environment to long-term health and lifespan. Progress in Biophysics and Molecular Biology, 2011;106(1):323-336. doi: 10.1016/j.pbiomolbio.2010.12.005

3. Chavey A., Movassat J., Portha B. Impact and Mechanisms of Pancreatic Beta-Cell Mass Programming by Maternal Diabetes-Insight from Animal Model Studies. In: Gestational diabetes. Radenkovic M. Ed. InTech, Croatia. 2011;pp201-227. doi: 10.5772/23027

4. Portha B., Chavey A., Movassat J. Early-life origins of type 2 diabetes: fetal programming of the beta-cell mass. Experimental Diabetes Research, 2011, doi:10.1155/2011/105076.

5. Yessoufou A., Moutairou K. Maternal diabetes in pregnancy: early and long-term outcomes on the offspring and the concept of "metabolic memory". Experimental Diabetes Research, 2011, doi:10.1155/2011/218598.

6. Fetita L-S., Sobngwi E., Serradas P., Calvo F., Gautier J-F. Consequences of fetal exposure to maternal diabetes in offspring. Journal of Clinical Endocrinology \& Metabolism. 2006, 91(10):3718-3724. DOI: $10.1210 /$ jc. 2006-0624

7. Pitale S., Sahasrabuddhe A. Fetal origin of vascular aging. Indian Journal of Endocrinology and Metabolism, 2011, 15(Supp14):S289-S297. DOI: 10.4103/2230$\underline{8210.86971}$
8. Luo Z-C., Xiao L., Nuyt A-M. Mechanisms of developmental programming of the metabolic syndrome and related disorders. World Journal of Diabetes, 2010,1(3):8998. DOI: $10.4239 /$ wjd.v1.i3.89

9. Perera F., Herbstman J. Prenatal environmental exposures, epigenetics, and disease. Reproductive Toxicology, 2011, 31(3):363-373. 10.1016/j.reprotox.2010.12.055

10. Drake A.J., Reynolds R.M. Impact of maternal obesity on offspring obesity and cardiometabolic disease risk. Reproduction, 2010, 140(3):387-398. doi: 10.1530/REP-10$\underline{0077}$

11. Bonetti PO, Lerman LO, Lerman A. Endothelial dysfunction a marker of atherosclerotic risk. Arteriosclerosis Thrombosis, and Vascular Biology, 2003, 23(2):168-175.

12. Pepine C.J. The impact of nitric oxide in cardiovascular medicine: untapped potential utility. The American Journal of Medicine, 2009,122(5):S10-S15.

DOI: $10.1016 /$ j.amjmed.2009.03.003

13. Förstermann U., Münzel T. Endothelial nitric oxide synthase in vascular disease from marvel to menace. Circulation, 2006, 113(13):1708-1714. doi: 10.1161/CIRCULATIONAHA.105.602532

14. Yu Q., Gao F., Ma X.L. Insulin says NO to cardiovascular disease. Cardiovascular Research, 2011, 89(3):516-524. DOI: $10.1093 / \mathrm{cvr} / \mathrm{cvq} 349$

15. Wu J.T. Circulating homocysteine is an inflammation marker and a risk factor of lifethreatening inflammatory diseases. $J$ Biomed Lab Sci, 2007, 19(4):107-111.

16. Faeh D., Chiolero A., Paccaud F. Homocysteine as a risk factor for cardiovascular disease: should we (still) worry about it? Swiss Medical Weekly, 2006, 136(47/48):745-156.

17. El-Bassiouni E., Helmy M., Abou R.N., ElZoghby S., Kamel M., Abou R.A. Embryopathy in experimental diabetic gestation: assessment of PGE2 level, gene expression of cyclooxygenases and apoptosis. 
British Journal of Biomedical Science, 2004, 62(4):161-165.

18. Salim M., Al-Matubsi H.Y., El-Sharaky A.S., Kamel M.A., Oriquat G.A., Helmy M.H., et al. The levels of vascular endothelial growth factor-A and placental growth factor-2 in embryopathy associated with experimental diabetic gestation. Growth Factors, 2009, 27(1):32-39.

DOI: 10.1080/08977190802587049

19. Arulmozhi D., Veeranjaneyulu A., Bodhankar S. Neonatal streptozotocininduced rat model of Type 2 diabetes mellitus: A glance. Indian Journal of Pharmacology, 2004, 36(4):217-221.

20. Kanauchi M., Yamano S., Kanauchi K., Saito Y. Homeostasis model assessment of insulin resistance, quantitative insulin sensitivity check index, and oral glucose insulin sensitivity index in nonobese, nondiabetic subjects with high-normal blood pressure. Journal of Clinical Endocrinology \& Metabolism, 2003, 88(7):3444-3446.

21. Guevara I., Iwanejko J., Dembinska-Kiec A., Pankiewicz J., Wanat A., Anna P., et al. Determination of nitrite/nitrate in human biological material by the simple Griess reaction. Clinica Chimica Acta, 1998, 274(2):177-188.

22. Gillman M.W. Developmental origins of health and disease. The New England Journal of Medicine, 2005, 353(17):18481850. DOI: 10.1056/NEJMe058187

23. Kamel M.A. Prenatal Effects of Different Intra-Uterine Milieus on Fetal Glucose Sensing Mechanisms during Gestation in Rats. Journal of Diabetes \& Metabolism, 2012, 3:181. DOI:10.4172/21556156.1000181.

24. Ong K.K. Catch-up growth in small for gestational age babies: good or bad? Current Opinion in Endocrinology,Diabetes and Obesity, 2007,14(1):30-34. doi: 10.1097/MED.0b013e328013da6c

25. Wells J.C., Chomtho S., Fewtrell M.S. Programming of body composition by early growth and nutrition. Proceedings of the Nutrition Society, 2007, 66(03):423-434. DOI: $10.1017 / \mathrm{S} 0029665107005691$
26. Barker D.J, Osmond C., Forsén T.J., Kajantie E., Eriksson J.G. Trajectories of growth among children who have coronary events as adults. New England Journal of Medicine, 2005, 353(17):1802-1809. DOI: 10.1056/NEJMoa044160.

27. Singhal A., Cole T.J., Fewtrell M., Deanfield J., Lucas A. Is slower early growth beneficial for long-term cardiovascular health? Circulation, 2004, 109(9):1108-1113. doi: 10.1161/01.CIR.0000118500.23649.DF

28. Singhal A., Fewtrell M., Cole T.J., Lucas A. Low nutrient intake and early growth for later insulin resistance in adolescents born preterm. The Lancet, 2003, 361(9363):1089-1097. doi:10.1016/S0140-6736(03)12895-4.

29. Ibáñez L, Ong K, Dunger DB, de Zegher F. Early development of adiposity and insulin resistance after catch-up weight gain in smallfor-gestational-age children. Journal of Clinical Endocrinology \& Metabolism, 2006, 91(6):2153-2158. DOI: $10.1210 /$ jc. 20052778.

30. Sherpa L.Y., Stigum H., Chongsuvivatwong V., Luobu O., Thelle D.S., Nafstad P., et al. Lipid profile and its association with risk factors for coronary heart disease in the highlanders of Lhasa, Tibet. High Altitude Medicine \& Biology, 2011, 12(1):57-63. DOI: 10.1089/ham.2010.1050

31. Lozano J.V., Pallarés V., Cea-Calvo L., Llisterri J.L., Fernández-Pérez C., Mart'iCanales J.C., et al. Serum lipid profiles and their relationship to cardiovascular disease in the elderly: the PREV-ICTUS study. Current Medical Research and Opinion, 2008, 24(3):659-670. 10.1185/030079908X273372.

DOI:

32. Lafontan M., Langin D. Lipolysis and lipid mobilization in human adipose tissue. Progress in Lipid Research, 2009, 48(5):275297. doi: 10.1016/j.plipres.2009.05.001

33. Lewis G., Zinman B., Uffelman K., Szeto L., Weller B., Steiner G. VLDL production is decreased to a similar extent by acute portal vs. peripheral venous insulin. American Journal of Physiology-Endocrinology and Metabolism, 1994, 267(4):E566-E572. 
34. Das U.N. Insulin: an endogenous cardioprotector. Current Opinion in Critical Care, 2003, 9(5):375-383.

35. Ji L., Fu F., Zhang L., Liu W., Cai X., Zhang L., et al. Insulin attenuates myocardial ischemia/reperfusion injury via reducing oxidative/nitrative stress. American Journal of Physiology-Endocrinology and Metabolism, 2010, 298(4):E871-E880. DOI: 10.1152/ajpendo.00623.2009.

36. Förstermann U. Nitric oxide and oxidative stress in vascular disease. Pflügers ArchivEuropean Journal of Physiology, 2010, 459(6):923-939. DOI: 10.1007/s00424-010$\underline{0808-2}$

37. Li H., Wallerath T., Münzel T., Förstermann U. Regulation of endothelial-type NO synthase expression in pathophysiology and in response to drugs. Nitric Oxide, 2002, 7(3):149-164.

38- Kamel M.A., Helmy M.H., Hanafi M.Y., Mahmoud S.A., Elfetooh H.A. Effect of Maternal Diabetes on Pre-and Post-Natal Redox Status of F1 Rat Offspring. Open Journal of Endocrine and Metabolic Diseases, 2014; 4: 111-127. DOI: 10.4236/ojemd.2014.45012

39. Drummond G.R., Cai H., Davis M.E., Ramasamy S., Harrison D.G. Transcriptional and posttranscriptional regulation of endothelial nitric oxide synthase expression by hydrogen peroxide. Circulation Research, 2000, 86(3):347-354.

40. Li L., Chen W., Rezvan A., Jo H., Harrison D.G. Tetrahydrobiopterin deficiency and nitric oxide synthase uncoupling contribute to atherosclerosis induced by disturbed flow. Arteriosclerosis, Thrombosis, and Vascular Biology, 2011, 31(7):1547-1554. DOI: 10.1161/ATVBAHA.111.226456.

41. Vollset S.E., Refsum H., Irgens L.M., Emblem B.M., Tverdal A., Gjessing H.K., et al. Plasma total homocysteine, pregnancy complications, and adverse pregnancy outcomes: the Hordaland Homocysteine study. The American Journal of Clinical Nutrition, 2000, 71(4):962-968.
42. Guilland J., Favier A., Potier de C.G., Galan P., Hercberg S. [Hyperhomocysteinemia: an independent risk factor or a simple marker of vascular disease?. 1. Basic data]. Pathologie-Biologie, 2003, 51(2):101-110.

43. Obeid R., Herrmann W. Homocysteine and lipids: S-adenosyl methionine as a key intermediate. FEBS Letters, 2009, 583(8):1215-1225. DOI: 10.1016/j.febslet.2009.03.038

44. Meigs J.B., Jacques P.F., Selhub J., Singer D.E., Nathan D.M., Rifai N., et al. Fasting Plasma Homocysteine Levels in the Insulin Resistance Syndrome The Framingham Offspring Study. Diabetes Care, 2001, 24(8):1403-1410.

45. Cho N.H., Lim S., Jang H.C., Park H.K., Metzger B.E. Elevated homocysteine as a risk factor for the development of diabetes in women with a previous history of gestational diabetes mellitus: A 4-year prospective study. Obstetrical \& Gynecological Survey, 2006, 61(2):86-87.

46. Selhub J. Homocysteine metabolism. Annual Review of Nutrition, 1999, 19(1):217-246.

47. Willette A.A., Gallagher C., Bendlin B.B., McLaren D.G., Kastman E.K., Canu E., et al. Homocysteine, neural atrophy, and the effect of caloric restriction in rhesus monkeys. Neurobiology of Aging, 2012, 33(4):670-680. DOI: 10.1016/j.neurobiolaging.2010.06.003

48. Dankner R., Geulayov G., Farber N., Novikov I., Segev S., Sela B. Cardiorespiratory fitness and plasma homocysteine levels in adult males and females. IMAJ, 2009, 12:78-82

49. Aparna P. Homocysteine and oxidative stress markers and inflammation in patients with coronary artery disease. Int J Biol Med Res, 2010, 1(4):125-129.

50. Hucks D., Thuraisingham R.C., Raftery M.J., Yaqoob M.M. Homocysteine induced impairment of nitric oxide-dependent vasorelaxation is reversible by the superoxide dismutase mimetic TEMPOL. Nephrology Dialysis Transplantation, 2004, 19(8):19992005. 
51. Domanic N., Gelisgen R., Civelek S., Demir A.S., Ural D., Andican G., et al. Homocysteine and nitric oxide in patients undergoing diagnostic coronary angiography. Acta Medica Okayama, 2006, 60(1):35-41.
52. Foncea R., Carvajal C., Almarza C., Leighton F. Endothelial cell oxidative stress and signal transduction. Biological Research, 2000, 33(2):86-96. 